rechtlicher Normen ab, erstaunt angesichts der zahlreichen dargestellten entgegenstehenden Beispiele.

Im das Luftrecht behandelnden zweiten Teil, der mit 10 Seiten recht knapp gehalten ist, wird vorwiegend dargestellt, welche bilateralen Bindungen die VRC eingegangen ist. Grundsätzlich hält die VRC, ihrem Sicherheitsbedürfnis entsprechend, strikt an ihrer ausschließlichen, auch der Höhe nach als unbegrenzt und unbegrenzbar angesehenen Territorialhoheit über dem Luftraum fest. Für vertraglich eingeräumte Úberflug- und Zwischenlandungsrechte gelten strenge Begrenzungen und Sicherheitsbestimmungen. Multilateralen Verträgen, aus denen sich auch Verpflichtungen, insbesondere auf haftungsrechtlichem Gebiet ergeben hätten, ist die VRC nicht beigetreten.

Vergleichsweise ebenfalls zu kurz kommt der unter der vielversprechenden Úberschrift "Environment" ganze 20 Seiten umfassende dritte Teil, der die Frage der Meeresverschmutzung nur anreißt und die atmosphärische Verschmutzung nur unter dem Gesichtspunkt der Gefährdung durch Atomwaffen behandelt. Angesichts dieser Selbstbeschränkung erstaunt die Aufnahme eines Teils "Bevölkerung" als Umweltverschmutzungsproblem. Ein Zusammenhang zwischen Bevölkerungswachstum und Umweltschäden wird von der VRC negiert, weil die Eröffnung und Nutzung natürlicher Ressourcen durch die Menschheit sich ständig ausweite. Daß die von der Autorin zunächst angeführte Begründung für diese Haltung (die Ausbeutung natürlicher Quellen sei unerschöpflich), auf einer fehlerhaften und teils unrichtig übernommenen Ubersetzung der hierfür zitierten Quelle beruht, wird erst im Schlußwort (S. 234/35) erwähnt. Hiermit verbindet die Autorin gleichzeitig den für jeden an chinesischer Völkerrechtsauffassung Interessierten wichtigen Hinweis, daß eine der Hauptschwierigkeiten im Verständnis der Haltung der VRC zum Völkerrecht die Gefahr der Mißinterpretation bei der Úbersetzung chinesischsprachiger Äußerungen in westliche Sprachen darstellt.

Karin Kammann

\title{
Oskar Weggel
}

\section{Chinesische Rechtsgeschichte}

E. J. Brill, Leiden, Köln, 1980, XI, 298 S., Gld. 128.—

Das Werk ist als Sechster Band der Vierten Abteilung ("China") des von dem Hamburger Orientalisten Berthold Spuler herausgegebenen Handbuchs der Orientalistik erschienen. Der Autor, der zu zahlreichen Fragen insbesondere modernen chinesischen Rechts publiziert hat, schildert die Entwicklungsgeschichte des klassischen Rechts von der Zhou-Zeit bis 1911, wobei er den wichtigsten Dynastien jeweils ein Kapitel widmet. Ausgehend vom Recht der Qing-Dynastie (1644-1911) berichtet er sodann vor allem über allgemeines Strafrecht, Verwaltung, Zivilrecht, strafrechtliche Einzeltatbestände. Am Ende dieses Abschnitts faßt Weggel Charakteristika des chinesischen Rechts zusammen, wobei er dessen Beharrungskraft besonders akzentuiert. Knapp 40 Seiten sind schließ- 
lich der Entwicklung zwischen 1911 und heute gewidmet. Die rechtspolitische Neuorientierung nach dem Tode Mao Tse-tungs wird noch nicht aufgearbeitet, wenngleich einige neue Gesetze bereits Erwähnung finden.

Philip Kunig

Wolfram Eberhard

Geschichte Chinas. Von den Anfängen bis zur Gegenwart

3. Auflage, 1980, 444 S., DM 25.-

Eberhard, der in Potsdam geborene Lehrstuhlinhaber für Sinologie in Berkeley, hat seine Gesamtdarstellung der chinesischen Geschichte erstmals 1971 vorgelegt. Die ersten 400 Seiten sind aus der Erstauflage übernommen, nur im Kapitel 'Nachkriegszeit ' hat der Autor Umstellungen und Erweiterungen vorgenommen. Das Kapitel über Taiwan ist um eine Seite ergänzt, der Volksrepublik sind 14 neue Seiten gewidmet worden. Den Schluß bildet ein Abschnitt 'Rückblick und Ausschau' (S. 428-431). Es versteht sich, daß Eberhard auf so wenig Raum keine detaillierte Darstellung oder gar begründete Einschätzung der Entwicklung des modernen China geben kann. So begnügt er sich mit der Mitteilung von Eckdaten und einigen, manchmal an der Oberfläche bleibenden Kommentaren. Als handliche deutschsprachige Einführung in die Geschichte des alten China steht der Band allerdings nach wie vor allein neben Herbert Frankes und Rolf Trauzettels 'Das chinesische Kaiserreich' (1968) und Wiethoffs 'Grundzügen' (1971), die in der Bibliographie erstaunlicherweise beide nicht die verdiente Erwähnung finden.

Philip Kunig

\section{Mitchell A. Seligson}

Peasants of Costa Rica and The Development of Agrarian Capitalism.

The University of Wisconsin Press, Madison 1980, 220 S., $21.50 \$$

Die vorliegende Länderstudie zeigt, wie zunächst durch die Einführung der Kaffeekultur (für den Weltmarkt), damit in Zusammenhang der Bau der Eisenbahn, die wiederum die Bananenexportkultur ermöglichte, dieses einst dünn besiedelte Land mit nur einer geringen sozialen Differenzierung und vorwiegend subsistent wirtschaftenden Kleinbauern, in den Weltmarkt integriert wurde. Dies führte zu "einem ständigen sozialen Abstiegsprozeß der armen Landbewirtschafter, die in zunehmendem Maße die Kontrolle über das Land verloren. Der Autor zeichnet dabei ein eher idyllisches Bild der Landbewirtschafter in der vor-kapitalistischen Gesellschaft (verglichen mit dem Zustand, der sie dann erwarten sollte): "The once proud yeoman who constituted the social backbone of the nation has slowly shipped into a position of insignificance alongside the powerful coffee 